\title{
Mobile Learning Platform: a case study of introducing m-learning in Tertiary Education
}

\author{
Nana Kofi ANNAN, George O. OFORI-DWUMFUO, and Morten FALCH
}

\begin{abstract}
This paper presents a study on a one year mlearning pilot project at Central University College in Ghana. This was done through a user trial, where the mlearning tool AD-CONNECT is introduced in 44 courses with a total of 500 students and 22 lecturers at the College. The paper reports on the first experiences gained by both teachers and students by asking the following questions: What are the perceptions of teachers on m-learning? What are the effects of m-learning on students? What does $\mathbf{m}$ learning contribute to face-to-face teaching and learning? Questionnaires were administered to students and lecturers to gather quantitative data on their views on the use of m-learning, particularly after using the ADCONNECT M-Learning system. Also, observations and interviews were used to collect data from users which provided us with some qualitative data.
\end{abstract}

Index Terms-Anywhere anytime, Education, learning, mlearning, teaching

\section{INTRODUCTION}

The Government of Ghana, in its ICT in Education policy of 2008, lays emphasis on educational institutions to be creative and innovative by adopting and adapting new appropriate technologies which are useful in enhancing teaching and learning for better results [1]. The world in the past five to ten years has experienced huge research into the use of mobile technology for teaching and learning as a new way of facilitating education in the mobile age [2], [3], [4].This has provided numerous frameworks and findings on how best mobile devices can be utilized in education to match the dynamics of society greatly influenced by diverse innovative technologies [5], [6], [7].

Africa with its challenges in meeting the education needs of its citizenry has a great opportunity to overcome its educational difficulties by carefully employing the use of mobile devices to support teaching and learning. This will go a long way in promoting sustainable education to large numbers of students anywhere anytime to meet the socio-economic

Manuscript received February 29, 2012. Mobile Learning Platform: a case study of introducing m-learning in tertiary education.

N. K. Annan, Centre for Communication, Media and Information Technologies (CMI) Aalborg University, Frederikskaj 12, $3^{\text {rd }}$ floor Sydhavn 17 DK2450 Copenhagen SV Denmark \& Wisconsin International University, P.O. Box LG 751, Legon, Accra Ghana (e-mail: annan@cmi.aau.dk).

G. Ofori-Dwumfuo, Methodist University College Ghana, Department of Information Technology, P. O. Box DC 940 Dansoman, Accra Ghana (g_ofori@yahoo.com)

M. Falch, Centre for Communication, Media and Information Technologies (CMI) Aalborg University, Frederikskaj 12, $3^{\text {rd }}$ floor Sydhavn 17 DK2450 Copenhagen SV Denmark (e-mail: falch@ cmi.aau.dk). needs of the people. 'I he students have the technology (mobile phone) in their hands and therefore educational practitioners have to leverage the use of mobile technology which has become a part of today's student's life to go along with their technology-inherited learning life-styles [8], [9], [10]. Mlearning will serve as a good platform to augment the face-toface classical way of providing education where teacher and student contact is mainly limited to a fixed location. Mlearning overcomes the limitation of static education to a more ubiquitous way of education delivery in social context [11], [12], [13].

Currently some m-learning pilot projects in Africa are making a successful head way after several years of experiments [14], [15], [16]. One of these success stories can be found in Ghana at the Central University College (CUC). Having used the AD-CONNECT M-Learning system on pilot basis for two years, CUC is now ready to do full adoption and implementation of m-learning to cover a student population of 10,000 starting from September 2011.

Although m-learning is quite new to the Ghanaian education community, the use of mobile phones for browsing the internet, sending short messages, watching movies, making money transfer, receiving bank statements and balances, listening to music, getting updates on stock markets and commodity prices, farm produce information etc are common. All these serve as a good acquaintance for a large number of people in Ghana especially teachers and students to use mobile phones for teaching and learning.

The purpose of this study was to observe the usage of AD-CONNECT M-learning system and gather feedback from users and also to solicit user opinions on the use of m-learning in tertiary education. The overall research objective of the study is to analyse how the use of m-learning tools can enhance the learning process in a tertiary learning environment. This is done through a user trial, where the mlearning tool AD-CONNECT is introduced in 44 courses at Central University College in Ghana. This paper reports on the first experiences gained by both teachers and students by asking the following questions: What are the perceptions of teachers on m-learning? What are the effects of m-learning on students? What does m-learning contribute to face-to-face teaching and learning?

\section{BACKGROUND AND MOTIVATION}

In today's modern society, ICT plays an important role in providing quality education in order to fulfill its human resources capacity building for a country so as to meet the demands of the labor market, locally as well as internationally. 
The Government of Ghana in 2000 enacted a policy that all computers and mobile phones will be imported duty free. This the Government did as a way of promoting the use of ICT in various sectors of the economy. This policy has enabled high import of mobile phones which has resulted in relatively cheap prices- a good sign for m-learning.

Mobile technology offers new cost effective ways of learning, but only limited research has been done on how these can be applied and how they will affect the learning process. Currently the computing power of smart phones has improved tremendously over the past few years such that these phones are capable of processing information as handheld computers. This makes mobile phones perform beyond just being used for making calls. These, among other factors, form the basis which has led to enormous research in m-learning implementation, adoption and diffusion in schools.

\section{WHAT IS M-LEARNING?}

Many researchers and educators view mobile learning as a descendant of electronic learning (e-learning). For instance, as cited by Laouris and Eteokleous [17], mobile learning is "elearning that uses mobile devices and wireless transmission". [7] Mostakhdemin -Hosseini and Mustajarvi view it as the evolution of e-learning; and ( [18] describe it as "occupying a sub-space within the e-learning space.

This paper agrees with the definition of m-learning by [3] that provides a roster of characteristics, thus:

"The capacity for learning anytime and anywhere through the use of multimedia (text, voice, image, or video) and communication (phone call, voiceltext messaging, e-mail, web access). This mode of teaching and learning provides realtime online interaction in a series of short burst learning activities, with features such as voice/video recording for storytelling or even a mobblogging journal."

Starting in the late 1990s Professor Mike Sharples of University of Nottingham directed an active research program to investigate mobile learning [19]. In 2000, computer learning consultant Clark Quinn provided one of the first definitions of mobile learning, which he described as: 'learning through mobile computational devices' [20]. Shepherd [21] says 'M-learning is not just electronic, it's mobile'. One feature of mobile learning is the opportunity to break away from teaching that takes place in a classroom, and to move to another location while communicating via information networks. Another distinctive feature of mobile learning is that it enables learners to enter an information network at the precise moment when necessary by using portable learning devices and wireless networks. The mobile environment integrates studies that take place on campus, at home or outside university facilities into one shared, flexible learning environment.

\section{WHY M-LEARNING?}

In today's society, students have access to handheld technologies that are more powerful and better connected than conventional desktop computers. These technologies do not only provide students with access to the internet but also serve as a mechanism for what has become their main mode of electronic communication: e-mail and instant messaging [22]. As a result of increased popularity, this phenomenon and demand of mobility have extended to the teaching and learning environment.

Since the start of the new millennium, the development and delivery of mobile learning have grown in visibility and significance as witnessed by the number of research projects and dedicated conferences and seminars [16].

Mobile technologies have profoundly impacted the way we learn and communicate in business, education, government, and society. It is a phenomenon that has been acknowledged across the globe and continues to impact various facets of our lives. As witnessed by its popularity, mobile innovation inspires flexibility and accessibility to learning and has the capacity to bridge the digital divide while transforming the way we teach and learn.

Greater amount of learning takes place outside the classroom jurisdiction and the current generation has integrated mobile technologies into their lives. Therefore it is incumbent on educators to take advantage of this reality through anywhere, anytime learning solutions, such as smart phones, mobile phones, tablets, notebooks and laptop computers to leverage these devices for learning purposes taking into consideration the fact that students are surrounded by portable devices which keep them in constant contact with their families, friends and the world. Students today absorb, interact with and create content outside of the classroom more than they do inside.

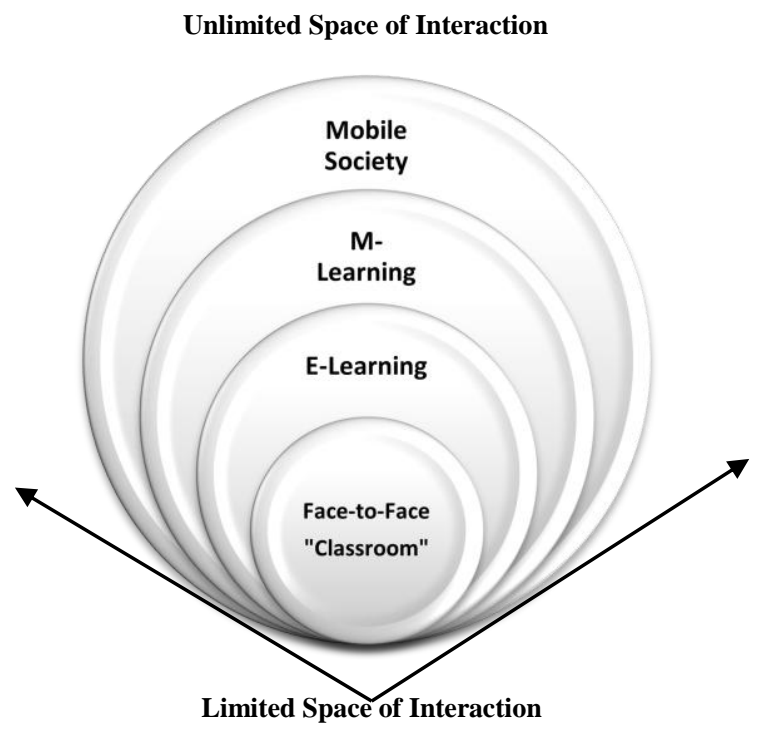

Fig- 1 is a conceptual framework which explains the amount of interaction and space offered by face-to-face, e-learning and m-learning in today's knowledge and mobile society. 


\section{THE “ANYWHERE”, “ANYTIME”, “ANY DEVICE” PHENOMENON}

Education delivery has come a long way and is advancing from a specific location context to ubiquitous space, which is teaching and learning anywhere, anytime with any device. This is a new paradigm in education which has received the attention of researchers over the past few years with several pilot projects being conducted across the globe.

"Anywhere" is a situation which is not limited to a specific location or venue. "Anytime" can be explained as an undecided time or wherever seems convenient or appropriate. 'Any Device" in this context refers to all types of computing devices which have the capabilities for teaching and learning. These devices include smart phones, mobile phones, PDAs, tablets, palmtop, notebooks, laptops and desktop computers. The integration of anywhere, anytime, any device with ICT, creates a Mobile Learning Platform (MLP) which offers numerous opportunities for education delivery in the $21^{\text {st }}$ century. This paper can confidently say that human-beings with the advancement in mobile computing are gradually attaining a "Virtual Omnipresence Status" (VOS) which apparently makes people feel like they are at anywhere anytime. The past five years have seen a rapid growth in research, development and deployment of mobile technologies to support learning. Although research in this area began with the seminal work of Kay and colleagues in the early 1970s with the Dynabook project from the Learning Research Group at the Xerox Palo Alto Research Center (Kay, A., \& Goldberg, A. , 1997), the convergence of technology and education started quite recently. The new technology includes multimedia-equipped smart phones, mobile phones, personal digital assistants (PDAs), tablets, palmtops, notebooks and laptop computers.

\section{The M-LEARNING CASE AT CENTRAL UnIVERSITY COLLEGE}

Central University College is a liberal arts institution located in Accra, the capital city of Ghana. The university was established in 1997 and currently has a total student population of ten thousand and two hundred teaching staff. The university, in March 2010, decided to take a bold step in harnessing mobile technology to facilitate teaching and learning to make teaching and learning available anywhere anytime any device. The university then collaborated with AD-CONNECT to conduct a pilot m-learning project in the University for a Section of the faculty and students.

The pilot project was conducted in all the two campuses of the university at Mataheko at Dansoman and Miotso near Tema in twelve (12) months from March 2010 to April 2011, which constitute two semesters. In all 44 courses including mathematics, English, bio-chemistry etc were used for the pilot. A total of 500 students and 22 lecturers were used for the pilot project. The subjects were picked randomly from level 100 to 400 with each level having a taste of the new learning technology.

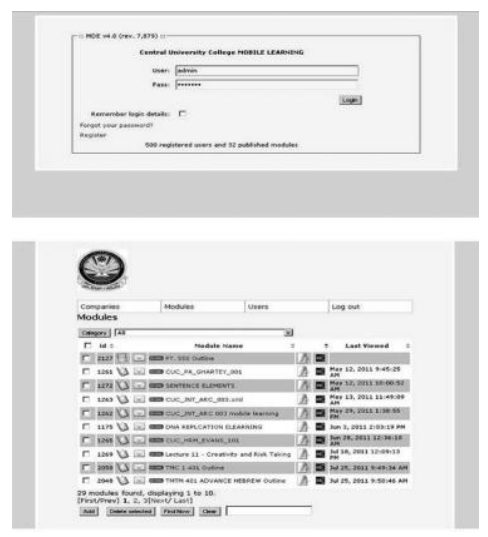

Fig. 2. This is a screen shot of the login and list of content on the m-learning system

A twelve month m-learning pilot project was conducted at Central University College (CUC). The study used participatory action strategy to investigate firsthand experience gained by both teachers and students on the use of $\mathrm{m}$-learning. The researchers were involved in the entire pilot project as facilitators. Observations, interviews and questionnaires were used to gather data from participants who directly or indirectly used the m-learning platform for either teaching or learning.

Different roles like teacher, student and technical support were played by the researchers as a way of fully being part of the project to obtain first-hand information from participants of the project in a natural setting. We also took part in the content development with the teachers and the technical support.

\section{DAta Collection Methods}

\section{A. OBSERVATION}

We were daily involved in the project as participants and facilitators. We created a good rapport with participating students and teachers which gave us cordial interaction with them throughout the entire period of the project. We monitored participants' general behaviour towards the project from all perspectives.

\section{B. INTERVIEWS}

In all, 10 students and 5 teachers were interviewed. The purpose of the interviews was to gather data on personal experiences and perception on the project. Students were interviewed in a relaxed environment. Some of the interviews were done at school cafeteria, library and under study trees on campus. While the interviews of students was informal, that of the teachers was formal and was conducted in their offices after appointments were booked and accepted. 


\section{QUESTIONNAIRES}

420 questionnaires were administered to students and teachers as a means to help collect some quantifiable data for quantitative analysis of their feedback. A variation of questions were asked including 5-point likert scale and "yes" and "no" questions.

\section{PARTICIPANTS}

The project was conducted mainly with teachers and students at all the CUC campuses. A total of 500 students and 22 teachers took part in the pilot exercise.

The following are statistics of the 500 students: 200 from level 100, 100 from level 200, 150 from level 300 and 50 from level 400. The 22 teachers had lectures with students at all the levels on different subjects.

\section{The Pilot PRoject}

AD-CONNECT, a mobile learning system was developed and mounted for CUC to provide m-learning platform for teaching and learning on pilot basis from March, 2010 to May, 2011. The m-learning solution from AD-CONNECT gave teachers the opportunity to publish simplified lecture notes, examinations, quizzes, questionnaires, assignments, poll and surveys with direct feedback to students with any kind of mobile device.

Teachers were given training on how to develop content for m-learning using learning mobile author (LMA). The LMA is a desktop tool for creating interactive modules integrated to mobile delivery and tracking system which allows content to be uploaded on the mobile learning platform for students to access. Students were also trained on how to effectively learn using the m-learning platform on their mobile phones.

After the training, lecturers were able to develop their own teaching content and they uploaded them onto the ADCONNECT m-learning platform for students to access before and after class at anytime anywhere. Students access the mlearning system with a mobile phone using mobile broadband internet facilities. Students "log-on" to the m-learning system with a unique ID which enable lecturers to track individual learning activities on the system. On the platform, student were able to read lecture notes, do assignment, quizzes, group work and exams in a ubiquitous environment with their mobile phones.

In all 44 courses including mathematics, English, biochemistry etc., a total of 500 students and 22 lecturers were used for the pilot project. The subjects were picked randomly from level 100 to 400 with each level having a taste of the new learning technology. Questionnaires were administered to students and lecturers of Central University College to gather quantitative data on their views on the use of m-learning particularly after using the AD-CONNECT M-Learning system. Also, interviews were conducted to solicit subjective opinions from users which provided us with some qualitative data. Summary of the results are high-lighted under findings with graphic representation of the data.
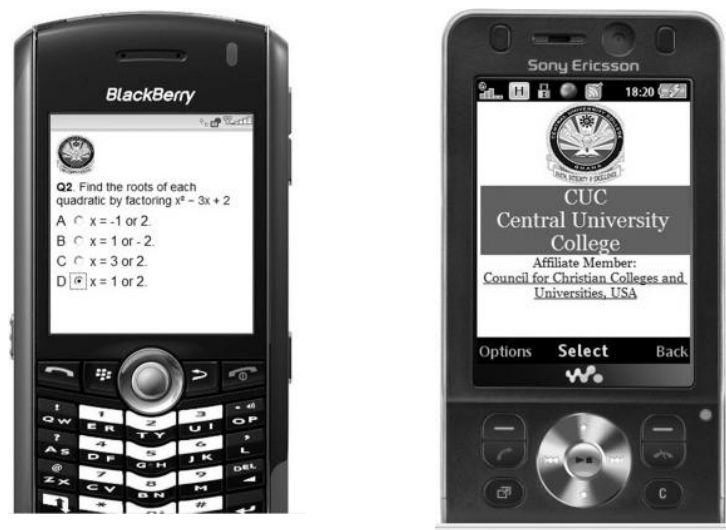

Fig. 3. A screen shot of users mobile phone. The pictures shows how content is displayed on the mobile phone.

\section{HOW THE AD-CONNECT M-LEARNING SYSTEM WORKS}

The teacher plays two main roles on the m-learning platform. The teacher doubles as a content developer and mentor user. First of all, the teacher develops appropriate content based on the institution's pedagogical framework. The education institution takes full ownership of the content which is then given to the content service provider (CSP) for publishing. The content service provider publishes the content by uploading the content onto the m-learning platform which is connected to the internet. The mobile internet service provider (MISP) serves as the medium through which users get access to the content. Thus the content is made available to all users via the MISPs. Users with their mobile phones using mobile broadband internet connect to the CSP to access content for learning. The users in this context are two; that is, the student who is basically a user as a learner and the teacher who is also a user as a mentor for the student in a social construction learning environment. Finally the teacher takes feedback from student users to make update and modification on content development.

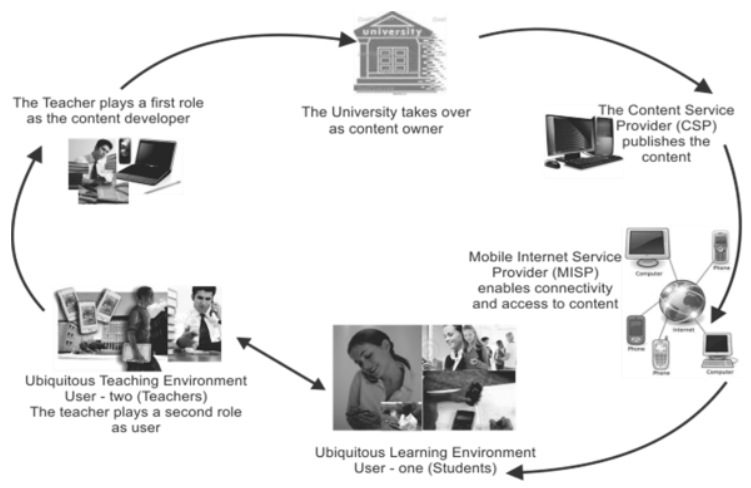

Fig. 4. This diagram shows the m-learning process at Central University Colleg-Ghana 


\section{FINDINGS}

The first thing that stands out in this project is the substantial social impact it produced in the CUC community which emphasized on the great support given to the project by the University Council, teachers and students involved. This showed that the m-learning technology is a tool that can be used to improve the quality of education delivery.

During the entire process we observed a high level of motivation in the students. This was due both to the expectation and changed pedagogic framework produced by the introduction and blend of m-learning, with face-to-face classroom setting mode of education delivery.

Some students said: "wow, this is different and great. It is an entirely new style of learning; it takes away fear and builds confidence in students. Learning with mobile phone is entertaining, stress free, didactic, and easier". Another also added: "It is a platform that engages our interest to learn new things and at the same time save time".

The report of the lecturers of Central University College to the Academic Board of the University stated that "Mobile learning enhances collaboration between students and lecturers, by lecturers sending their notes to them and getting instant feedback. This would prevent students from being idle with their time and put them into better use, by learning their notes and doing their assignments. It enables lecturers monitor progress of their students through mobile learning. Mobile learning helps lecturers assess students with assignments and MidSemester Examinations and get immediate response (when Multiple Choice questions are adopted).

Some benefits of using Mobile Learning include, track students understanding of lessons taught. what students do with their lecture notes, delivering assignments, conducting polls and surveys, instant examination results and help students to revise before coming for lectures, However students must be encouraged to have compatible phones and schools should provide reliable wireless internet services to ensure that the process works smoothly. Lecturers are of the view that Mobile Learning will be useful to both students and lecturers and will promote healthy academic environments.

The result of the survey questionnaire gave a strong indication that most students and teachers answered strongly agreed or agreed to the questions which were positive on m-learning with an insignificant number of students and teachers disagreeing. Fig 5 gives a graphical representation of the results.

\section{TEACHERS}

We observed that some of the teachers were not comfortable with the system for several reasons thus: (1) some teachers are not familiar with using computers to develop content for teaching. (2) Some teachers do not have smart phones. (3) The perception of some teachers that more time is needed for content development. (4) Lack of motivation from school authorities (5) Intellectual property rights (6) attitudinal issues. (7) Pedagogical issues (8) cost of mobile broadband to the teacher (9) mobile learning extends working hours of teachers beyond the classroom providing $24 \mathrm{hrs}$ access to students. (10) Lack of instructional design facilitators. (11) Inadequate teaching assistants to assist lecturers on content development. (12) Inconsistent internet connectivity at school and home makes it difficult to publish or upload content on the mlearning platform frequently. (13) Mobile phones and smart phones have small keypads which sometimes makes it difficult to use if you have to type many words. (14) Good and sophisticated smart phones are relatively expensive. (15) The need for m-learning policy in Ghana

\section{STUDENTS}

Contrary to the teachers, students were highly enthusiastic to use their mobile phones to access learning materials on the mlearning platform. Students were rather unhappy about the unsatisfactory internet service by service providers in Ghana.

On the other hands both teachers and students admitted that the m-learning platform offers the needed capacity for enhancing teaching and learning anywhere anytime and with any device. They did not hesitate to outline the relevance of m-learning in tertiary education to the research team as follows: (1) ubiquitous teaching and learning (2) Increase student and teacher interaction anywhere anytime (3) Boost confidence of timid students (4) Instant multiple choice knowledge assessment feedback (5) Makes it easier to handle large numbers of students with less difficulty (6) If m-learning is well designed it can save teachers enough time to do research instead of spending all their time attending to students face-to-face and marking large volumes of students scripts all the time. (7) It supports constructivism, behaviouralism and cognitive models of pedagogy. (8) 100\% of students have mobile phones and smart phones which are suitable for m-learning. (9) M-learning is good for distance education and lifelong learning (10) It supports both personalised and social collaborative learning (11) It provides flexibility in teaching and learning (12) It provides just-intime teaching and learning (13) The mobile phone attracts the interest of students to learn.

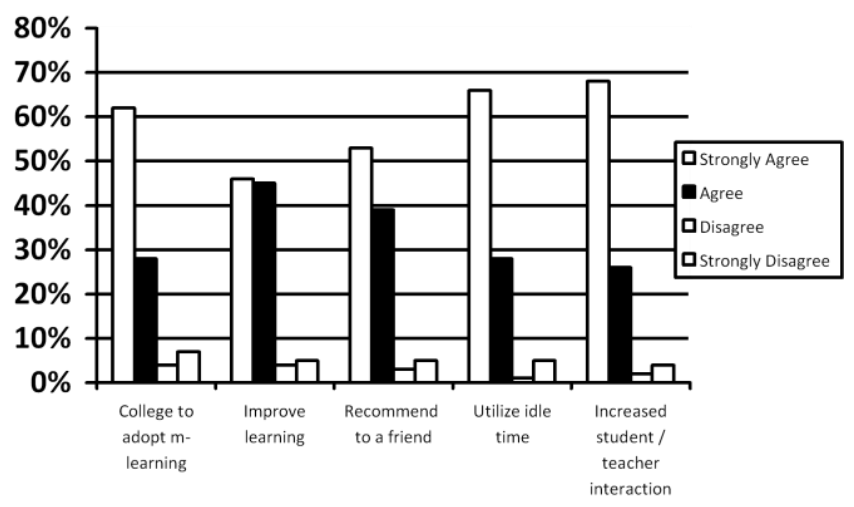

Fig. 5. Graphical presentation of questionnaires administered to some teachers and students. 


\section{DISCUSSION AND CONCLUSION}

Our observations and survey gave strong indications that there is the need for more pilot projects on m-learning to be conducted in especially higher education institutions in Ghana to offer teachers and students the chance to experience teaching and learning anywhere, anytime with any device.

One of the serendipities of mobile communication technology is the computing abilities of the technology which makes it convenient for teaching and learning anywhere anytime. This overcomes the limitations of traditional face-to-face classroom education. The findings of the study provided some answers to the research questions on the perceptions of teachers on $\mathrm{m}$ learning, the effects of m-learning on students and the contribution it adds to face-to-face teaching and learning. Although the findings from the study cannot be generalized, it has generated some basic information for further research in the area of m-learning.

\section{REFERENCE}

[1] Dadebo, E. K, et al, "ICT in Education Policy Framework, Government of Ghana," 2008.

[2] G. Caudil, "The growth of m-learning and the growth of mobile computing: Parallel developments.," The International Review of Research in Open and Distance Learning, pp. 8(2) 1492-3831, 2007.

[3] Shih, Y., \& Mills, D., "Setting the new standard with mobile computing in online learning.," International Review of Research in Open and Distance Learning, pp. 8(2), 17pp., 2007.

[4] G. Qinyang. (2003) Teaching English with Technology, 3(2). [Online]. http://www.iatefl.org.pl/call/j nt13.htm

[5] Sharples, M., Taylor, J., \& Vavoula, G., "Towards a theory of mobile learning," in Proceedings of mlearn 2005 conference, Cape Town, 2005

[6] O' Malley, C., Vavoula, G., Glew, J., Taylor., Sharples, M., \& Lefrere, P. (2003) Mobilearn project deliverable. [Online]. http://www.mobilearn.org/download/results/guidelines.pdf

[7] Mostakhdemin-Hosseini, A., \& Tuimala, J., "Mobile learning framework.," Proceedings IADIS International Conference Mobile Learning 2005, pp. 203-207, 2005.

[8] Castleman, W. A., Harper, R., Herbst, S., Kies, J., Lane, S., \& Nagel, J., "The impact of mobile technologies on everyday life. In CHI '01 Extended Abstracts on Human Factors in Computing Systems (Seattle, Wahington, March 31 - April 05, 2001).," CHI '01. ACM, pp. 227-228. DOI:19.1145/634067. 634202, 2001.

[9] Jacob, S. M., \& Isaac, B, "Mobile technologies and its impact: An analysis in higher education context. ," International Journal of Interactive Mobile Technologies, p. 2(1), 2008.

[10] J. Traxler, "Learning in a mobile age.," International Journal of Blended Learning, , pp. 1(1), 1-12, 2009.

[11] S. J. Gedded, "Mobile Learning in the 21st Century: Benefit for learners.," Knowledge tree e-journal, pp. 1-13, 2004.

[12] Sharples, M., Taylor, J., \& Vavoula, G., "A Theory of learning for the mobile age.," In R. Andrews \& C. Haythornthwaite (Eds.), The Sage handbook of e-learning research, pp. (pp. 221-247)., 2007.

[13] Wang, M., Shen, R., Novak, D., \& Pan, X., "The impact of mobile learning on students' learning behaviours and performance: Report from a large blended classroom.," British Journal of Educational Technology, pp. 40(4), 673-695, 2009.

[14] Boyinbode, O. K., \& Akinyede, R. O., "Mobile learning: An Application of mobile and wireless technologies in Nigeria learning system," IJCSNS International Journal of Computer Science and Network Security, vol. 8 No.11, November 2008.

[15] J., Traxler, "Current State of Mobile Learning," International Review on Research in Open and Distance Learning (IRRODL), vol. 8, No.2, 2007.
[16] J. Traxler, "Defining mobile learning.," IADIS International Conference Mobile Learning 2005, pp. 261-266, 2005.

[17] Laouris, Y., \& Eteokleous, M. (2005, October) Proceedings of the 4th World Conference on Mobile Learning. [Online].

[18] Georgiev, T., Georgieva, E., \& Smrikarov, A, "Me-learning: A new stage of e-learning.," Proceedings of the International Conference Systems and Technologies, CompSysTech 2004, pp. IV.28, 1-5, 2004.

[19] M. Sharples, "The design of personal mobile technologies for lifelong learning.," Computers \& Education, 34, 177-193., 2000.

[20] C. Quinn, "mLearning: Mobile, Wireless and In-Your-Pocket Learning.," Line Zine Magazine. http://www.linezine.com/2.1/features/cqmmwiyp.htm, 2000.

[21] C. Shepherd, "M is for Maybe. Tactix: Training and communication technology in context.," http://www.fastrakconsulting.co.uk/tactix/features/mlearning.htm, 2001.

[22] C. Murray, "Mobile learning in the classroom.," pp. 45(1), 48-54, 2010.

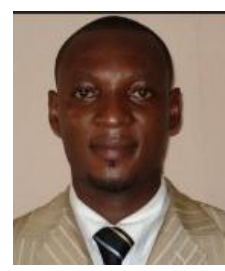

Nana Kofi Annan is a Ph.D student at Centre for Communication Media and Information Technologies (CMI) Aalborg University Copenhagen. $\mathrm{He}$ is researching in the area of mobile technologies, mobile computing, mobile learning and educational technologies. His $\mathrm{PhD}$ research is concerned with the advancement of mobile technologies over the past few years with a special interest in leveraging its capacities to facilitate tertiary education, using mobile learning platform.

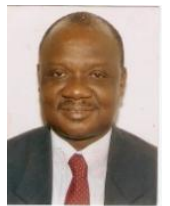

Dr. George Orelens Ofori-Dwumfuo is a Senior Lecturer at the Methodist University College Ghana, Accra where he heads the Department of Information Technology. Dr. OforiDwumfuo has a first degree in Mathematics from Ghana, and a PhD. Degree in Computer Science from the United Kingdom. He has over twenty years experience as Research Fellow and University Lecturer. He also has ten years experience as Head of IT Department in a Bank. His institutional address is Methodist University College Ghana, P O Box DC 940, Accra, and his research interest is in the effect of computerization on the Ghanaian society.

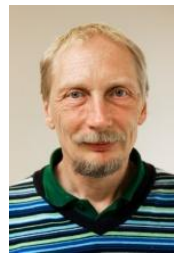

Morten Falch Ph.D is Associate Professor at Centre for Communication Media and Information Technologies (CMI) at Aalborg University Copenhagen. His research includes analysis of markets for IT and telecom services, economic analysis of applications and telecommunication networks and services, e-government, and tele-centres, regulation of the telecom sector. He teaches and supervises $\mathrm{PhD}$ students (currently 3 ) in the same areas. He has also conducted a large number of consultancies for national and international organisations such as ITU, UNCTAD, the World Bank and the National Telecom Agencies in Denmark, Norway and Sweden. Since 1990 Morten Falch has been involved in various research and education projects in Ghana. This includes creation of a masters programme in ICT in collaboration with Ghana Telecom University College. 